\title{
UM PASSO À FRENTE E DOIS ATRÁS: REFLEXÕES SOBRE A CONSTITUIÇÃO DA PRÁXIS NO CURSO DE PEDAGOGIA
}

One step abead and two behind: reflections on the constitution of praxis in the pedagogy course

Un paso adelante y dos atrás: reflexiones sobre la constitución de la praxis en el curso de pedagogía

Antonia Alves Pereira Silva *

https://doi.org/10.38117/2675-181X.formov2021.v3i1n5.131-151

\section{Resumo}

Neste artigo discuto a formação do pedagogo situando-a no âmbito da política educacional defendendo que ela seja realizada pautada numa epistemologia da práxis. Considero que os documentos normativos que subsidiam essa formação, as Resoluções CNE/CP n ${ }^{\circ}$ 1/2006 e CNE/CP n. ${ }^{\circ}$ 2/2015, encontram-se vinculadas às perspectivas críticas da educação e contribuem para elaboração de projetos pedagógicos que viabilizam a práxis como um projeto a ser alcançado. Esse projeto formativo é afetado pela publicação da Resolução $\mathrm{CNE} / \mathrm{CP} \mathrm{n}^{\circ}$ 2/2019 ao conceber a formação docente pautada nas competências com implicações significativas para a Pedagogia. A discussão é ancorada na política de formação docente, no conceito de práxis e na ideia de uma formação docente crítico-emancipatória. Os dados empíricos foram extraídos de pesquisa realizada junto a estudantes do curso de Pedagogia da Universidade Estadual do Piauí em que se analisou a constituição da práxis enquanto princípio epistemológico formativo.

Palavras-chave: Pedagogia; Formação; Práxis; Diretrizes Curriculares. 


\begin{abstract}
In this paper I discuss the pedagogical training, situating the scope of educational policy, defending that it is carried out according to the epistemology of praxis. I consider that the normative documents that subsidize this training, as Resolutions CNE/CP $\mathrm{n}^{\circ}$ 1/2006 and CNE / CP n 2/2015, are linked to critical perspectives of education and contribution for the elaboration of pedagogical projects that make feasible to praxis as um project to be reached. This training project is affected by the publication of Resolution CNE/CP $\mathrm{n}^{\circ}$. $2 / 2019$ to conceive of teacher training based on competencies with significant implications for Pedagogy. A discussion is anchored in the policy of teacher training, in the concept of praxis and the idea of a critical-emancipatory teacher training. The empirical data are extracted from a research carried out together with students from the Pedagogy course of the State University of Piauí in which the constitution of the practice was analyzed as an epistemological formative principle.
\end{abstract}

Keywords: Pedagogy; Training Teacher; Praxis; Curricular Guidelines.

\title{
Resumen
}

En este artículo analizo la formación del pedagogo, ubicándola en el ámbito de la política educativa, argumentando que debe realizarse desde una epistemología de la praxis. Creo que los documentos normativos que sustentan esta formación, las Resoluciones CNE / CP n ${ }^{\circ}$ 1/2006 y CNE / CP n. 2/2015, están vinculados a las perspectivas críticas de la educación y contribuyen a la elaboración de proyectos pedagógicos que viabilicen la praxis como proyecto a realizar. Este proyecto formativo se ve afectado por la publicación de la Resolución CNE / CP n. ${ }^{\circ}$ 2/2019 al concebir la formación del profesorado a partir de competencias con implicaciones significativas para la Pedagogía. La discusión se ancla en la política de formación docente, en el concepto de praxis y en la idea de formación docente crítico-emancipadora. Se extrajeron datos empíricos de una investigación realizada con estudiantes del curso de Pedagogía de la Universidad Estatal de Piauí en la que se analizó la constitución de la praxis como principio formativo epistemológico.

Palabras clave: Pedagogía; Formación; Práctica; Directrices curriculares.

\section{Introdução}

O intenso debate educacional que se desenvolveu no Brasil a partir dos anos 1980 com o processo de redemocratização do país afetou significativamente a área de formação de professores. As discussões enunciavam a urgente necessidade de reformulação nos 
currículos dos cursos de licenciatura objetivando a formação de profissionais com uma visão crítica da sociedade e comprometidos com princípios de uma educação democrática.

No caso do curso de Pedagogia, aliada a essa questão, outras demandas históricas se faziam presentes no debate como a identidade do curso e a separação teoria e prática (BRZEZINSKI, 1996), frequentemente citados como fragilidades na formação. Ademais, o curso não possuía Diretrizes Curriculares que norteassem a elaboração das propostas pedagógicas pelas instituições formadoras, o que permitia a criação de cursos com os mais diversos perfis, dificultando o debate sobre a identidade do pedagogo e a qualidade na formação.

Por esse motivo, a aprovação das Diretrizes Curriculares Nacionais de Pedagogia - DCNP, através do Parecer CNE/CP no 5/2005 e Resolução CNE/CP no 1/2006, representa um marco na história do curso. Embora esse processo tenha sido longo e marcado por disputas quanto aos sentidos do que deveria significar ser pedagogo e o curso de Pedagogia e as DCNP não representem um consenso entre os educadores da área, a sua aprovação permite olhar para o processo de formação nas IES a partir de um referencial legal, teórico e epistemológico que enriquece o debate na área.

Assim, o arcabouço legal norteador da formação docente no País, e da Pedagogia em particular, a Resolução CNE/CP n ${ }^{\circ}$ 02/2015 e a Resolução CNE/CP n ${ }^{\circ}$ 01/2006, tem contribuído para a promoção de experiências formativas significativas no campo da docência, permitindo questionar a definição de novas diretrizes para formação docente por meio da aprovação intempestiva da Resolução CNE/CP nº 2/2019.

Neste artigo discuto a formação do pedagogo a partir da construção teórica da área de formação de professores e de uma pesquisa realizada no curso de Pedagogia da Universidade Estadual do Piauí (UESPI). A pesquisa teve como objetivo analisar o currículo do curso de Pedagogia à luz dos seus elementos curriculares, identificando processos e práticas que na percepção dos sujeitos se desenvolvam numa perspectiva de unidade teórico-prática. Para este artigo é feito um recorte onde apresento dados da pesquisa documental e das falas dos estudantes relativos às experiências curriculares vividas durante a formação analisando-os a partir dos elementos constitutivos do conceito de práxis (VASQUEZ, 2011).

O texto está organizado em quatro seções. Além desta introdução discuto a política de formação docente e o curso de Pedagogia, a práxis como princípio formativo, dados da pesquisa de campo no curso de Pedagogia, os impactos da Resolução CNE/CP n 02/2019 para o curso de Pedagogia e considerações finais. 


\section{Política de formação docente e o curso de Pedagogia}

O curso de Pedagogia foi criado em 1939, através do Decreto-Lei nº 1.190, que no âmbito da Universidade do Brasil criou a Faculdade Nacional de Filosofia e dentre seus cursos, o de Pedagogia. Desde a sua criação o curso passou por embates e questionamentos quanto à sua identidade, currículo e o tipo de profissional a ser formado, se técnico/especialista em educação ou docente (BISSOLLI DA SILVA, 2003). Uma das explicações para essa situação era a imprecisão legal que caracterizou o funcionamento do curso por décadas.

Ao longo de sua história as regulações subsequentes, através dos Pareceres CFE $n^{\circ}$ 251/62 e 252/69, não conseguiram tocar nas questões mais conflitantes referentes à formação do pedagogo, o que intensificou no meio acadêmico o debate acerca da necessidade de diretrizes curriculares para curso que pudessem nortear essa formação e enfrentar a problemática da identidade do pedagogo.

No escopo dos movimentos pela redemocratização do país, nos anos 1980, é forjada uma concepção de pedagogo vinculada ao movimento pela formação de professores que tem na Associação Nacional pela Formação dos Profissionais em Educação (Anfope) grande expressão nessa luta. A Anfope articulou o pensamento de diversas entidades de educação que disputavam a concepção de ser professor. Foi a partir desse debate que se configurou a noção da docência como base de todo educador e a defesa de uma base comum nacional de formação desse profissional tendo como princípios: sólida formação teórica e interdisciplinar, unidade teoria-prática, trabalho coletivo e interdisciplinar, compromisso social e político com um projeto emancipador, valorização do profissional da educação, gestão democrática e, avaliação e regulação dos cursos de formação (ANFOPE, 2010).

No que tange ao curso de Pedagogia defendia-se a necessidade de reformulação curricular que, para além da formação técnica predominante, viabilizasse a formação de profissionais com uma visão crítica acerca da sociedade, comprometidos com princípios de uma educação democrática, além de buscar resolver problemas históricos na formação do pedagogo, dentre os quais a problemática da identidade do curso e da separação teoria e prática (BRZEZINSKI, 1996). Esses princípios nortearam a elaboração das Diretrizes de Pedagogia cuja aprovação ocorreu no ano de 2006, quase quatro décadas após a criação do curso. 
Assim, a Resolução CNE/CP nº1/2006 passa a ser o principal instrumento legal para orientação às IES quanto à elaboração e reformulação dos projetos de curso. Conforme Artigo $4^{\circ}$ do referido Documento,

O curso de Licenciatura em Pedagogia destina-se à formação de professores para exercer funções de magistério na Educação Infantil e nos anos iniciais do Ensino Fundamental, nos cursos de Ensino Médio, na modalidade Normal, de Educação Profissional na área de serviços e apoio escolar e em outras áreas nas quais sejam previstos conhecimentos pedagógicos (BRASIL, 2006).

A produção das DCNP é resultado de uma intensa disputa de projetos que pleiteavam a definição da identidade do pedagogo que, por sua vez, está relacionada ao tipo de curso projetado, se licenciatura ou bacharelado (AGUIAR; MELO, 2005; SCHEIBE, 2007). Portanto, a sua aprovação com essa caracterização não foi uma unanimidade, mas representou um divisor na história do curso. A expectativa em torno desse documento era não somente no sentido de orientação para elaboração dos currículos, mas também que pudesse representar um caminho no sentido de enfrentar e superar questões críticas do curso e da Pedagogia. Sobretudo, relativas à identidade do pedagogo, perfil profissional, estrutura curricular, dentre outros.

A despeito da controvérsia em torno das DCNP comungo do pensamento de Aguiar; Melo (2005), Scheibe (2007) e considero que elas representam um norteamento legal importante para formação do pedagogo e sua abrangência oferece muitas possibilidades para pensar essa formação numa perspectiva crítica-emancipatória, apresentando uma compreensão da prática pedagógica enquanto práxis (VASQUEZ, 2011).

Além da Resolução CNE/CP $\mathrm{n}^{\circ} 1 / 2006$ com o respectivo Parecer que fundamentam a formação em Pedagogia, as Instituições de Ensino Superior necessitam seguir também os demais documentos que regulamentam a formação de professores para elaboração de seus Projetos Pedagógicos de Curso - PPC. Neste caso, a Resolução CNE/CP no 2/2015 que definiu Diretrizes Curriculares Nacionais para a formação de professores, inicial e continuada.

A Resolução $\mathrm{CNE} / \mathrm{CP}$ n $^{\circ}$ 2/2015 resultou de um amplo processo de discussão pautado na reflexão histórica acerca da formação de professores realizado pelas diversas entidades educacionais e científicas de luta pela educação, a Anfope, Associação Nacional de Pesquisa e Pós-Graduação em Educação (Anped), o Fórum de Diretores de Faculdades/Centros de Educação das Universidades Públicas Brasileiras (Forumdir), a Associação Nacional de Administradores Educacionais (Anpae) e Confederação 
Nacional dos Trabalhadores em Educação (CNTE). Portanto, apresenta uma concepção de educação como fenômeno amplo e emancipatório e a docência é percebida como sendo realizada a partir de um conjunto de conhecimentos interdisciplinares envolvendo as dimensões técnicas, políticas, ética, estética caracterizado por sólida formação envolvendo conteúdos e metodologias diversas (BRASIL, 2015).

Para Dourado (2015), a Resolução de CNE/CP nº 2/2015 pode ser considerada inovadora e ousada em termos de pensar a formação de professores, pois projeta essa ação

[...] priorizando as Universidades, por meio da efetiva articulação dessas IES com os entes federados, seus sistemas e redes, instituições de educação superior e instituições de educação básica, sem descurar da efetiva participação dos fóruns permanentes de formação e demais instâncias como conselhos nacional, distrital, estaduais e municipais e respectivos fóruns. (DOURADO, 2015, p. 315).

De acordo com Bazzo e Scheibe (2019), um diferenciador entre a Resolução de 2015 e a Resolução CNE/CP n ${ }^{\circ}$ 1/2002 que antes norteava a formação docente, está na compreensão de que na formação devem ser priorizados conhecimentos em detrimento das competências, uma vez que são os saberes que permitirão aos docentes enfrentar a imprevisibilidade da prática educacional e não competências pragmáticas descontextualizadas. Outro ponto a ressaltar é a concepção de integração entre formação inicial e continuada; bem como articulação entre formação e carreira docente.

Assim, tanto as DCNP quanto a Resolução de 2015 estão fundadas em um discurso do campo progressista da educação que direcionam a formação no curso de Pedagogia para possibilidade de uma atuação profissional futura numa perspectiva de prática enquanto práxis (VASQUEZ, 2011).

Porém, com a mudança de governo em 2015 através do impeachment da presidenta Dilma Rousseff, a Resolução de 2015 passou por obstáculos na sua efetiva implementação, especialmente, após a aprovação da Base Nacional Comum Curricular BNCC uma vez que o discurso na esfera governamental passa a ser a produção de novas Diretrizes de formação docente em consonância com a Base o que efetivamente ocorre no ano de 2019 com a aprovação da BNC-Formação através da Resolução CNE/CP no 2 de 2019. Assim, delineia-se um novo modelo de formação para os professores no país. Qual a concepção de formação constante na atual normativa legal? Quais as implicações para o curso de Pedagogia? Voltarei posteriormente a essas questões. 


\section{Práxis como princípio formativo do pedagogo}

A compreensão da práxis como princípio epistemológico formativo no curso de Pedagogia está sustentada em princípios acerca da formação de professores elaborados no âmbito da perspectiva crítica da educação ratificada pela Anfope e, ao mesmo tempo, no entendimento da Pedagogia como área de conhecimento que tem na práxis educativa seu objeto de estudo.

No debate sobre a formação de professores a relação entre teoria e prática foi muitas vezes foco de discussão dada a relevância dessas duas dimensões para formação docente. Na perspectiva crítica da educação advoga-se que esses elementos sejam abordados de forma unitária, ou seja, enquanto práxis, visando superar a histórica dicotomia existente no processo formativo. $\mathrm{O}$ entendimento desses aspectos de forma dicotômica ou apenas justapostos na formação do pedagogo tem dificultado a compreensão da prática docente como práxis incidindo, pois, na qualidade da atuação profissional.

A compreensão de práxis aqui assumida está ancorada em Vázquez (2011) que concebe práxis como atividade consciente capaz não somente de interpretar o mundo, mas também de transformá-lo. O autor frisa que práxis, enquanto atividade prática, não pode ser confundida com o significado de prático-utilitário das necessidades imediatas que separam o sujeito do objeto, conforme entendido pelas perspectivas pragmáticas.

práxis é, na verdade, atividade teórico-prática, isto é, tem um lado ideal, teórico, e um lado material, propriamente prático. Com a particularidade de que só artificialmente, por um processo de abstração, podemos separar, isolar um do outro[...] (VÁZQUEZ, 2011, p. 264).

Portanto, a atividade para ser considerada práxis requer um grau de consciência do sujeito acerca da ação realizada; consciência que é refletida tanto sobre a ação quanto sobre a própria consciência acerca da mesma. A materialidade da práxis não significa que toda ação prática possa ser compreendida como práxis. Vázquez $(2011$, p. 221) afirma que "toda práxis é atividade, mas nem toda atividade é práxis". Essa consideração é fundamental para desconstrução de algumas noções de prática que permeiam o cenário educacional e que não estão vinculadas à práxis transformadora.

Para Vázquez (2011) alguns elementos são fundamentais para compreensão da atividade como práxis: a) conhecimento da realidade a ser transformada; b) conhecimento dos meios e sua utilização, ou seja, das técnicas necessárias para transformar a prática; c) conhecimento da prática acumulada em forma de teoria que 
sintetize ou generalize a prática e uma dada esfera de atuação; d) uma atividade finalista, ou seja, antecipação dos objetivos que se quer alcançar.

Vários autores (FRANCO, 2008; CURADO SILVA, 2011, 2017; NORONHA, 2010) têm discutido a prática educativa enquanto práxis. Franco $(2008$, p.80) destaca que "na dimensão educativa, prática deve ser vista sempre no sentido de práxis educativa", que comporta uma dimensão ética, de intencionalidade que direciona a ação a fim de transformar o objeto. Ela argumenta, fundamentada na concepção dialética, que teoria e prática não estão contrapostas e envolve sempre uma dimensão e transformação do objeto e do sujeito.

O pressuposto da educação e do trabalho docente enquanto práxis conduz a discussão da formação docente no sentido de uma epistemologia que tenha na práxis o seu norte, como propõe Noronha (2010). Para a autora é necessário pensar a práxis como uma categoria epistemológica na formação dos professores, o que nos levaria

a uma diferenciação de fundo conceitual entre o que pode ser chamado de uma "atividade de formação de professores" e uma "práxis de formação de professores"; entre uma "atividade educativa" e uma "práxis educativa". Estes problemas nos levam a pensar que estamos diante da questão de como construir uma Epistemologia na Formação dos Professores. (NORONHA, 2010a, p. 15, grifos da autora).

Assim como Noronha, entendo que pensar a formação de professores é ponderar como o conhecimento é construído no âmbito desses cursos. Como a autora ressalta, pensar a questão das condições objetivas de formação dos professores é colocá-la em termos de um problema de conhecimento. Pois, segundo ela,

Ao tomar como ponto de partida que o conhecimento é construído no interior de uma pedagogia da práxis bem como a consideração do professor e do aluno como sujeitos históricos que ao mesmo tempo em que são modificados pelas circunstâncias são capazes de nela atuar, modificando-as, torna-se possível que uma práxis transformadora possa ser desenvolvida no processo pedagógico de formação de professores e alunos (NORONHA, 2010, p. 17, grifos da autora)

A adoção de uma epistemologia da práxis como princípio para formação de professores sustenta-se na ideia conceitual de que a prática educativa realizada nos diversos contextos educacionais tem como propósito contribuir para transformação dos sujeitos envolvidos.

Para Curado Silva (2017), considerar a práxis como princípio formativo é defender uma formação docente comprometida com uma educação crítica emancipadora. 
A autora explicita que a formação docente para emancipação se sustenta na compreensão do significativo papel da educação para construção da consciência crítica, necessária à análise da realidade; o que é fundamental no processo de busca da liberdade humana. Neste sentido, a formação do professor necessita fundamentar o futuro profissional para a capacidade de análise e síntese da realidade educacional. Pois,

[...] Este, como trabalhador da educação, necessita ter elementos teórico-metodológicos para realizar sua atividade de forma crítica e politizada, levando em consideração as relações de poder desde o espaço da escola até o contexto mais amplo, a fim de interferir na realidade (CURADO SILVA, 2017, p. 132).

A partir do exposto compreendo que trazer os elementos conceituais da práxis como princípios para formação docente significa, além do já apontado, viabilizar nesse processo as relações entre teoria e prática de modo unitário, no qual o pensar e o fazer pedagógico possam ser objeto de reflexão constante visando aperfeiçoamento da práxis. Esse processo exige reconhecer que existe uma diversidade de saberes que são necessários à formação do docente, não apenas o saber acadêmico. Portanto, na prática formativa, é necessário o exercício cognitivo que permita ao aluno, futuro professor, articular os saberes que tem acesso ao chegar à universidade com os demais saberes de sua existência enquanto sujeito histórico-social.

Para que isso ocorra é necessário pensar o currículo de forma que as diversas áreas do conhecimento consigam dialogar entre si através do planejamento das atividades docentes; considerar as atividades de planejamento educacional e execução da prática educativa como ações próprias de um mesmo sujeito pensante (práxis criadora); viabilizar estratégias de ensino que, norteadas pelo saber científico, tenha como foco a práxis real onde a educação se manifesta assim como os sujeitos a quem ela é dirigida, bem como criar situações pedagógicas nas quais o aluno seja confrontado com a realidade e suas contradições; nesse confronto ele exercita a possibilidade de construção do seu conhecimento como resultado da interação entre a teoria e a prática; entre conhecimento científico e saber experiencial.

\section{Perspectivas curriculares da práxis no curso de Pedagogia da UESPI}

A pesquisa empírica citada neste texto foi realizada na UESPI, no curso de Pedagogia - Campus Torquato Neto. Teve como objetivo geral analisar o currículo do curso de Pedagogia, à luz dos seus elementos curriculares, identificando processos e práticas que na percepção de professores e alunos se desenvolvam numa perspectiva de 
construção da dimensão teórico-prática e foi desenvolvida no âmbito de minha pesquisa de doutoramento. A produção do conhecimento considerou aspectos macrossociais e microcontextuais (BRANDÃO, 2001). A coleta de dados envolveu: análise de documentos que subsidiam a formação em Pedagogia e o Projeto Pedagógico do Curso PPC; entrevistas com professores e grupo focal com estudantes. Participaram da pesquisa oito professores responsáveis por disciplinas do II ao IX período do curso e 48 (quarenta e oito) estudantes desses mesmos períodos.

Para essa discussão trago dados que permitem refletir acerca da constituição da práxis no processo formativo. Levamos em consideração os elementos indicados por Vázquez (2011) como próprios do conceito de práxis: conhecimento da realidade, conhecimento dos meios e sua utilização, conhecimento da prática acumulada e conhecimento atividade finalista. Para os limites desse texto trarei alguns dados referentes ao sentido de teoria e prática no PPC e na percepção dos estudantes, o conhecimento da realidade e percepção da prática acumulada.

Em relação à análise documental um dos objetivos foi verificar como a dimensão teoria-prática é abordada no PPC. O Projeto em análise foi implementado em 2013 e tem como objetivo formar profissionais docentes para atuar na educação infantil, anos iniciais do ensino fundamental e gestão escolar.

O texto do PPC ressalta que a concepção de formação está ancorada nos documentos da ANFOPE e nas DCNP e que, em sintonia com a concepção defendida nesses documentos, visa a superação de problemas antigos do curso tais como a separação entre os componentes teóricos dos práticos e a formação fragmentada, gerando dicotomia entre o pensar e o fazer na educação (PIAUÍ/PPC, 2013).

Referências às dimensões teoria e prática aparecem em diversas passagens do Projeto. Por exemplo, ao citar que a proposta está pautada em "sólida fundamentação teórica acerca do fenômeno educacional" [...], "garantia de unidade entre teoria e prática, vivenciada de forma diversificada ao longo do curso e através de estágios supervisionados" (PIAUÍ/PPC, 2013, p. 11) e ao explicitar os princípios da Proposta destacando que no Projeto a teoria e a prática pedagógica são entendidas "como um todo indissociável na vivência de formação do aluno” (PIAUÍ/PPC, 2013, p. 19).

Esses trechos indicam a intencionalidade de colocar em relevo teoria e prática no processo de formação ressaltando-se em alguns extratos uma abordagem unitária dos termos. Isso pode ser constatado ao explicitar que o propósito é formar o pedagogo para uma atuação no sentido de práxis. Textualmente específica: “o compromisso com uma 
formação capaz de gerar uma práxis pedagógica competente por parte dos egressos da UESPI" (PIAUÍ/PPC, 2013, p.12).

Em relação à compreensão dos estudantes acerca da teoria e prática, bem como de sua importância na formação do pedagogo, os dados indicaram a existência de dois sentidos: às vezes de forma cingida, mas também numa perspectiva indicativa de uma relação dialética. A fala a seguir ilustra a primeira perspectiva.

A teoria é muito importante. A teoria é o que eu aprendi e a prática é onde eu estou executando o que eu aprendi. Apesar que tem muita teoria que a gente não consegue levar para a prática. $(E 4 B 8)^{l}$

Nessa ótica teoria é aquilo que deve vir antes da prática e a prática é vista como espaço de aplicação da teoria, ou seja, há um local para cada uma delas. Essa concepção representa uma das visões predominantes acerca de teoria e prática, como coisas distintas que não se relacionam (CANDAU; LELIS, 2011).

A segunda percepção, que foi predominante entre os discentes, remete a uma relação mais dialética dessas dimensões e à perspectiva de práxis de Vázquez (2011)

A teoria, ela fundamenta as nossas futuras experiências; é uma relação que está bem conectada a questão da teoria e da prática; porque para você chegar na prática você precisa ter um conhecimento teórico e aí para você também ter esse conhecimento teórico você precisa da prática para poder fixar esse conhecimento, numa relação indissociável. (E1B6)

[...] Então a teoria ela ajuda bastante, mas eu vejo que eu vou realmente consolidar a partir do momento que eu realmente estiver na escola; eu vou ter até uma capacidade maior de me aprofundar sobre aquela teoria (E6B6)

Em relação ao conhecimento da realidade procuramos saber se durante a formação o conjunto de disciplinas e práticas curriculares permitiram ao aluno uma aproximação com a realidade em que ele desenvolverá suas funções depois de formado; se ele conhece o objeto sobre o qual deverá incidir sua ação transformadora enquanto professor. $\mathrm{O}$ conhecimento da realidade educacional, mais especificamente da escolar, exige uma aproximação com essa realidade, a busca de conhecer a instituição escolar com seus determinantes contextuais.

Nesse sentido, o processo formativo precisa favorecer o debate acerca do que é a escola, sua função social, histórica, os elementos contextuais que a definem, seus sujeitos

\footnotetext{
${ }^{1}$ Os estudantes foram identificados por números e pelo Bloco de matrícula.
} 
e práticas, dentre outros. Trata-se de uma forma de conhecimento que é teoria e prática e pode ocorrer de diversas formas, conteúdos, autores, observações de situações reais, relatos de experiências para análise, realização de pequenos projetos etc. Esse conjunto de reflexões deverá subsidiar o aluno, futuro professor, na análise do real, tendo em mente uma realidade desejada, que se queira transformar.

Quanto a esse aspecto os estudantes responderam afirmativamente, ou seja, que o curso proporciona o conhecimento da realidade. Porém, destacaram que a visão da realidade só é completa quando vão às escolas e que alguns conteúdos poderiam ser mais abordados. A fala a seguir ilustra isso.

Sim, com certeza. Até porque nós tivemos oportunidades de vivenciar várias vezes fora da universidade, observação de outras disciplinas e em espaços não escolar também, que é importante. [...] e isso é bem interessante porque nós tivemos várias oportunidades de fazer essa observação nas escolas públicas e ver a dinâmica de como as pessoas trabalham. (E7B7)

A realidade dos espaços de atuação se mostra para os estudantes, por vezes, na forma de desafio. Quando se referem aos conteúdos ou situações que poderiam ser melhor abordadas no curso se referem a saber lidar situações conflituosas, como pais que são usuários de drogas, traficantes. Para os estudantes essas situações geram insegurança.

Esse aspecto remete ao caráter de imprevisibilidade inerente à educação e de uma realidade educacional complexa, dinâmica e de difícil apropriação. Curado Silva (2017) salienta que o trabalho com a epistemologia da práxis oferece os elementos para conhecimento e análise da realidade e suas contradições sendo necessário compreender que a realidade não se constitui em uma presença objetiva e monolítica. É necessário frisar a impossibilidade de apropriação da realidade enquanto totalidade. Porém, é fundamental a criação de estratégias de ensino que enfatizem a relação entre o particular e o universal na realidade educacional. Pois como afirma Vázquez (2011) a realidade precisa ser apropriada para que haja uma práxis adequada.

Vázquez (2011) aborda que, juntamente com o conhecimento da realidade, é necessário conhecer a finalidade do objeto sobre o qual deverá incidir a ação. Neste caso, a função da educação e o papel do pedagogo. As falas dos estudantes evidenciam uma compreensão da educação coerente com o sentido amplo da palavra. Referem que a educação tem uma finalidade humanizadora; formar o cidadão, mas o cidadão crítico; que o professor deve ser o multiplicador de conhecimentos significativos que sejam capazes de transformar a realidade. A fala a seguir é bem ilustrativa. 
[...] O professor, ele tem o papel de educar, então ele tem essa formação de ir bem além; a questão de formar pessoas, construir seres humanos críticos; dele construir a criticidade da pessoa para que ela futuramente possa ser independente. (E7BO)

Quanto à categoria conhecimento da prática acumulada o propósito foi abordar questões que permitissem inferir, a partir dos discursos dos estudantes, se durante a formação tiveram a oportunidade de apropriar-se dos conhecimentos produzidos na área da educação que subsidie sua ação sobre o objeto, a prática educativa. Saliento, neste caso, os conhecimentos teóricos e práticos que fazem parte do currículo do curso de Pedagogia. Vázquez (2011) considera que a transformação da realidade ocorre pela mediação de recursos e técnicas que poderão auxiliar o sujeito na sua atividade transformadora. Entendo que a apropriação dos conhecimentos pedagógicos assume esse caráter de mediadores na transformação da realidade do trabalho do docente.

Sobre esse aspecto os estudantes apontaram conteúdos e disciplinas que permitem considerar que houve uma apropriação dos meios necessários para intervenção na realidade educacional. Dentre os conteúdos mais citados destacamos: conhecimentos sobre o desenvolvimento da criança, noções de como a criança aprende, concepções de infância ao longo da história, organização de práticas pedagógicas para crianças pequenas (educação infantil), processo de aprendizagem para crianças com necessidades educacionais diferenciadas, relação entre a escola e a sociedade, etnocentrismo, organização do processo didático (planejamento de aulas), saberes sobre a subjetividade das pessoas.

A gente trabalha com crianças. Então a gente vê exatamente cada fase daquela criança. [...] (E13B9)

A gente estava em uma CMEI aí chega uma criança batendo, zangada. Ai já penso: 'de que maneira vou fazer para acalmar ele?’ Eu já procuro me vigiar nessa questão do olhar diferente em relação a atitude de cada criança. Para mim foi muito legal chegar na SEMEC estar muito mais preparada. (E7B7).

Porém, a aquisição de conhecimentos que possibilitem a mediação com a realidade revela-se ainda parcial uma vez que os estudantes apontam suas carências relativas a saberes para uma adequada intervenção, sobretudo, junto a crianças com necessidades educacionais especiais, conhecimentos de novas tecnologias para processo de ensino-aprendizagem e como enfrentar a pressão do cotidiano escolar.

Além de conteúdos disciplinares os estudantes ressaltaram atividades curriculares desenvolvidas que, para eles, contribuíram para ampliação das aprendizagens, a exemplo das atividades realizadas no espaço da Brinquedoteca em algumas disciplinas, os projetos realizados nas escolas, as observações nas CMEIs (Centros Municipais de Educação 
Infantil) com posterior discussão do que foi vivenciado, participação nos Programas de formação docente (PIBID), de pesquisa (PIBIC) e de extensão (PIBEU), as atividades de Estágio Supervisionado.

[...] Essas vivências são muito enriquecedoras por estar vivenciando esses espaços, esse cotidiano escolar, para nos dar um suporte maior para observar como que acontece, se eu falei diferente ou não, a gente fala muito sobre isso. E eu acho que esses programas PIBEU, PIBID e outros estágios também contribuem [...] porque tudo que a gente vê aqui na academia a gente vê acontecendo lá. (E3B6)

As falas abordam estratégias metodológicas utilizadas pelos professores que mostram articulação teórico-prática realizadas tanto no espaço da universidade como também nas escolas. Quando a estudante cita a sua atitude de 'parar' diante do comportamento de uma criança e buscar em seu repertório de conhecimentos a melhor maneira de agir naquela situação, está oferecendo indícios de uma preparação técnica advinda de uma teoria e prática acumuladas na área (VÁZQUEZ, 2011).

Os dados apresentados na pesquisa empírica indicam que o processo de formação no curso de Pedagogia norteado por suas Diretrizes Curriculares cria possibilidades para pensar a formação numa perspectiva crítica, pautada na unidade teoria-prática. Compreendo com Bernstein (1996), que a política educacional se caracteriza por processos de recontextualização. Nesse sentido, a materialização da política em um projeto pedagógico de curso resulta de interações e reelaborações que ocorrem no âmbito das instituições. Portanto, seria um equívoco afirmar que o currículo do curso de Pedagogia analisado, ou de qualquer outro, que apresente elementos de uma práxis formativa seja decorrência exclusiva do norteamento das Diretrizes. Todavia, estou convicta de que a produção política do campo recontextualizador oficial (BERNSTEIN, 1996) favorece a criação de determinados cenários formativos que se inserem em uma perspectiva mais progressista.

Nesse sentido, pretendo retomar a discussão acerca das novas Diretrizes Curriculares que subsidiam a formação dos professores, a Resolução CNE/CP n 2/2019, e criação da Base Nacional Comum para essa Formação, refletindo acerca das implicações desse documento para a formação no curso Pedagogia em particular. 


\section{O curso de Pedagogia sob a ótica da Resolução CNE/CP 02/2019: avanços e retrocessos}

A homologação da Resolução CNE/CP n. 2/2019 em dezembro de 2019 é mais uma etapa no conjunto de medidas da política educacional em processo de implementação no país desde o impeachment da presidenta Dilma Rousseff em 2016. A mudança de governo imprimiu um novo formato ao modo de produção das políticas educacionais, refletidas de forma inconteste na maneira como passou a se desenvolver a elaboração e aprovação da BNCC e as DCNs do Ensino Médio. A aprovação da BNCC serviu para impulsionar a defesa de mudanças no processo de formação de professores notadamente a substituição das Diretrizes de 2015, uma vez que a concepção de formação docente presente nessa Resolução não estaria em consonância com a BNCC.

No âmbito do governo federal iniciou-se um processo de elaboração de novas diretrizes para formação docente cujo processo se desenvolveu à revelia das entidades acadêmicas com histórica expressão na luta e defesa da educação e da formação docente. Com a chegada ao poder do governo conservador de extrema direita de Jair Bolsonaro, estratégias antidemocráticas no modo de produção das políticas se intensificaram e, ao final de 2019, novas Diretrizes para formação docente foram aprovadas incluindo uma Base Nacional Comum de Formação (BNC-Formação). O que ocorreu de forma intempestiva sem processos coletivos de discussão e negociação, porém, materializados a partir de interesses diversos (FARIAS, 2019).

A aprovação da Resolução CNE/CP n 2 de 2019 ensejou uma série de reações e críticas de autores e entidades acadêmicas (ANFOPE, 2020) tanto no que tange ao seu processo de elaboração e aprovação, conforme citado, mas, sobretudo, em virtude do seu conteúdo, ou seja, da concepção de formação docente projetada.

De antemão destaca-se o fato de que a Resolução de 2019 estabelece uma relação hierárquica intrigante ao colocar a formação de professores sob a tutela da BNCC. Ao fazer essa afirmação não estou desconsiderando a necessária relação que deve existir entre a formação docente e os diversos níveis de ensino, mas enfatizando que compreendo o significado de ser professor numa perspectiva ampla, para além do domínio de conteúdos estabelecidos no currículo da educação básica. Sobretudo, quando o entendimento de currículo é restrito a conteúdos de ensino; visão essa predominante na BNCC. Portanto, a formação docente restrita à viabilização do cumprimento do que está prescrito na BNCC enfatiza a dimensão técnica do professor, restringindo também o significado da educação enquanto processo de formação plena definido constitucionalmente. 
Outro aspecto ressaltado nas reflexões de diversos autores (BAZZO; SCHEIBE, 2019, DOURADO, 2015) é o fato de que na BNC- Formação a ênfase do processo é dada à aquisição de competências e habilidades. Isso evidencia o retorno à concepção de formação docente pautada nos aspectos pragmáticos da profissão. Tal concepção, ainda presente no cenário educacional, norteava todo o texto das Diretrizes de Formação docente de 2002. Nesse sentido, a Resolução de 2019 que suplanta a de 2015 com o argumento de propor uma inovação ao processo formativo representa um evidente retrocesso teórico e epistemológico.

Cabe ressaltar que a Resolução de 2015 apresenta um texto resultante de uma discussão histórica e política acerca da formação docente articulando formação inicial, continuada, formação e carreira docente como estratégia de valorização profissional e resgata os princípios da Base Comum Nacional defendidos pela Anfope. Esses aspectos são negligenciados na Resolução de 2019. Supõe-se, assim, que o único elemento simbolizador de uma identidade docente advinda da BNC-Formação é dado pela apropriação/execução da BNCC.

No que se refere à Pedagogia a Resolução ignora a discussão histórica em relação ao curso e a existência das DCNP que normatiza a sua formação. Ao fazê-lo, os legisladores não agem por displicência, mas visando pôr em pauta uma outra lógica formativa. As DCNP definem para os cursos de Pedagogia uma carga horária mínima de $3.200 \mathrm{~h} / \mathrm{a}$ e concebem a formação integrada do pedagogo, ou seja, forma simultaneamente para a docência e as atividades de gestão educacional. É esse modelo formativo que está ameaçado.

Na Resolução de 2019 a formação para gestão educacional é concebida como um aprofundamento de 400 h/a acrescidas à carga horária básica de 3200 h/a, totalizando 3600 h/a para os cursos de Pedagogia. Percebe-se aqui algumas questões preocupantes. Primeiro a negação da construção histórica sobre o curso que resultou em um modelo de formação integrada por entender " [...] a integralidade do ato educativo e pedagógicodocente, numa perspectiva teórico-prática de busca da sua especificidade teórica no pluralismo de seus aportes (ciências da educação) e das diversas docências[...] (AGUIAR; MELO, 2005, p. 122).

Em segundo lugar, ao conceber a formação em gestão educacional como núcleo de aprofundamento, algo a ser acrescido, abre margem para que essa formação seja identificada aos moldes do que ocorria na década de 1970, à semelhança das habilitações. Esse modelo formativo contribuiu para acirrar os problemas relativos à identidade do 
pedagogo, a fragmentação da noção de trabalho docente e acentuação da dicotomia teoria e prática.

A noção da formação integrada do pedagogo, tendo a docência como base, parte de uma compreensão da docência em sentido amplo que envolve o domínio dos conhecimentos a serem ensinados em sala de aula, mas também um saber sobre a escola enquanto espaço de formação humana, inserida em uma realidade complexa e multideterminada. Essa percepção oferece subsídios para pensar a atuação do pedagogo enquanto práxis reflexiva, calcada no conhecimento da finalidade de sua ação, da realidade em que ela se desenvolve e mediada por saberes acumulados (VÁZQUEZ, 2011).

Além disso a Resolução prevê que a formação do docente para atuar na educação infantil e anos iniciais do ensino fundamental ocorra em cursos separados, sendo que metade da carga horária total da formação -1600 h/a- deve ser destinada ao estudo das competências relativas à BNCC. As DCNP concebem a educação como processo amplo realizado a partir da interação entre instituições, sujeitos e saberes diversificados. Priorizar a articulação desses aspectos quando se trata da educação de crianças é ainda mais importante. Assim, a formação de professores de forma separada fragiliza a compreensão de educação como fenômeno multireferencial e reforça a noção dos saberes relativos à docência como algo cristalizado, fixo em um tempo espaço e uma noção de infância universalizada. $\mathrm{O}$ estabelecimento de metade da carga do curso exclusivo para estudo de competências da BNCC atribui à formação um caráter técnico, pragmático. Dificultando, pois, a realização do trabalho docente como algo socialmente qualificado.

A pesquisa empírica citada neste texto indicou que a formação no curso de Pedagogia tem contribuído para que os estudantes compreendam a educação enquanto fenômeno amplo e percebam suas conexões com o contexto social, além de perceberem as fortalezas e fragilidades da própria formação, aspectos que vão ao encontro de uma formação crítica. Essa construção só é possível a partir de uma sólida fundamentação teórica acerca dos fundamentos da educação e que que tem sua carga horária drasticamente reduzida com a atual Resolução.

Portanto, compreendo que a BNC-Formação representa uma grande ofensiva ao curso de Pedagogia, à sua história e às suas diretrizes construídas de forma democrática e participativa. Representa ainda um ataque às práticas formativas que vem sendo realizadas País afora que visam contribuir para formação de um profissional com uma visão crítica da educação. Entendo que após mais de uma década de aprovação das Diretrizes de Pedagogia faz-se necessário uma avaliação acerca de seus reflexos na 
formação de pedagogos, implicando em possíveis alterações. Porém, defendo que isso resulte de uma ação avaliativa envolvendo entidades científicas, instituições formadoras, sistemas de ensino, dentre outros, em um processo democrático participativo.

\section{Considerações Finais}

O ponto de partida de nossa discussão neste artigo foi o processo de formação no curso de Pedagogia pautando essa reflexão em aspectos históricos do curso, na política educacional de formação docente e análise empírica. Acredito na importância do curso de Pedagogia, enquanto curso de formação de professores para atuar na educação de crianças, considerando a possibilidade de que essa atuação se faça de modo crítico, reflexivo, comprometido com a aprendizagem das crianças. Para tanto, defendo que a práxis reflexiva seja o eixo central dessa formação auxiliando os futuros pedagogos no processo de interpretação e reflexão sobre a realidade educacional.

A definição das DCNP contribuiu para elaboração de propostas curriculares com uma concepção de pedagogo comprometido com as teorias críticas da educação sintonizados com valores de uma sociedade socialmente mais justa e democrática. Os dados da pesquisa empírica abordados neste artigo como: visão crítica sobre educação, conhecimento da realidade e aquisição de saberes que possam mediar a práxis, evidenciam a viabilidade da formação práxis no curso, permitindo a defesa dos instrumentos normativos que orientam a formação do pedagogo, as Resoluções CNE/CP n. 1/2006 e $n^{\circ}$ 2/2015, rejeitando a proposta formativa da BNC-Formação por substituir a noção de práxis por uma visão pragmática da prática pedagógica.

Dessa forma, é possível questionar a proposição de novas diretrizes para formação docente que imprimem uma concepção de formação de professores e pedagogo que permitem identificar o trabalho desses profissionais com a sua dimensão técnica calcada em competências instrumentais. Nesse sentido, é necessário questionar também esse modelo de formação por estar inserido numa lógica de educação neoliberal que visa implementar no âmbito das escolas a padronização curricular, processos de avaliação externa com fins de responsabilização (HYPOLITO, 2019) e o controle da formação docente que viabilize tais mudanças.

Por fim, saliento a necessidade de resistência por parte dos professores e das IES a essa normativa por seu caráter autoritário e por desprezar os processos históricos nos quais se assentam o debate acerca da formação de professores, reafirmar a defesa da 
formação do pedagogo com base na Resoluções CNE/CP n ${ }^{\circ}$ 1/2006, bem como reforçar nesse processo a práxis como princípio epistemológico formativo viabilizando uma formação docente comprometida com uma educação crítica emancipatória.

\section{Referências}

AGUIAR, M.A.S.; MELO, M.M.O. Pedagogia e as diretrizes curriculares do curso de pedagogia: polêmicas e controvérsias. Revista Linhas Críticas, Brasília, DF, v. 11, 2005. Disponível em https://periodicos.unb.br/index.php/ Acesso em: 1 de maio de 2019.

ANFOPE. Documento Final do XVIII Encontro Nacional da Associação Nacional pela Formação dos Profissionais da Educação, Goiânia, (2010).

ANFOPE. Manifesto da Anfope em Defesa da democracia. Abril de 2020. Disponível em https://www.anfope.org.br/entidades-nacionais-lancam-manifesto-contra-adesqualificacao-da-formacao-dos-professores-da-educacao-basica/

BAZZO, V.; SCHEIBE, L. De volta para o futuro... retrocessos na atual política de formação de professores. Revista Retratos da Escola, Brasília, v. 13, n. 27, p. 669-684, set./dez. 2019. Disponível em: http://retratosdaescola.emnuvens.com.br/rde>. Acesso em 03 de junho de 2020.

BISSOLLI DA SILVA, C. S. B. da. Curso de Pedagogia no Brasil: história e identidade. $2^{a}$ edição revista e atualizada, SP: Autores Associados, 2003. (Col. Polêmicas do nosso tempo; 66.

BRANDÃO, Z. A Dialética micro/macro na sociologia da educação. Cadernos de Pesquisa, São Paulo, n.113, p. 153-165, jul. 2001. Disponível em https://www.scielo.br/pdf/cp/n113/a08n113.pdf Acesso em 1 de novembro de 2019.

BERNSTEIN, B. A estruturação do discurso pedagógico: classe, códigos e controle. Vozes: Petrópolis, 1996.

BRASIL. Ministério de Educação e do Desporto. Conselho Nacional de Educação. Diretrizes Curriculares Nacionais para o Curso de Pedagogia. Resolução CNE/CP nº. 1/ 2006. DF, 2006.

Ministério de Educação e do Desporto. Conselho Nacional de Educação. Diretrizes Curriculares Nacionais para o Curso de Pedagogia. Parecer CNE/CP nº. 5/2005. DF, 2005.

Ministério de Educação e do Desporto. Conselho Nacional de Educação. Define as Diretrizes Curriculares Nacionais para a formação inicial em nível superior e para a formação continuada. Brasília. Resolução CNE/CP n. 02/2015. 
Ministério de Educação e do Desporto. Conselho Nacional de Educação. Institui a Base Nacional Comum Curricular. Brasília. Resolução CNE/CP n. 02/2017.

Ministério de Educação e do Desporto. Conselho Nacional de Educação. Define as Diretrizes Curriculares Nacionais para a formação inicial de professores para Educação Básica e institui a Base Nacional Comum para Formação de professores da Educação Básica (BNC-Formação). Diário Oficial da União. Brasília. Resolução CNE/CP n. 02/2019.

BRZEZINSKI, I. Pedagogia, pedagogos e formação de professores. Brasília, Papirus. 1996.

CANDAU, V. M. F. LELIS, I. A. A relação teoria-prática na formação do educador. In: CANDAU, V. M. F. (Org.). Rumo a uma nova Didática. 21ª . ed. Petrópolis: Vozes, 2011.

CURADO SILVA, K. A. P. C. A formação de professores na perspectiva críticoemancipadora. Linhas Críticas, Brasília, DF, v. 17, n. 32, p. 13-31, jan./abr. 2011. Disponível em< http://repositorio.unb.br/bitstream/10482/9461/1/> Acesso em 2 de jan. de 2018.

CURADO SILVA, K. A. P. C. Epistemologia da práxis na formação de professores. Revista de Ciências Humanas - Educação, v. 18, p. 15, 2017. Disponível em http://revistas.fw.uri.br/index.php/revistadech/article/view/2468. Acesso em 03/8/2019.

DOURADO, L. F. Diretrizes curriculares nacionais para a formação inicial e continuada dos profissionais do magistério da educação básica: concepções e desafios. Educação $e$ Sociedade. Campinas, vol. 36, n. 131, p. 299-324, junho 2015. Disponível em http://www.scielo.br/scielo.php?pid Acesso em 03 de novembro de 2019.

FARIAS, I. M. S. de. O Discurso Curricular da proposta para BNC. Revista Retratos da Escola, Brasília, v. 13, n. 25, p. 155-168, jan./mai. 2019. Disponível em: $<$ http//www.esforce.org.br> Acesso em 6 de novembro de 2019.

FRANCO, M. A. A Pedagogia como ciência da educação. 2. ed. São Paulo: Cortez, 2008.

HYPOLITO, A. M. BNCC, Agenda Global e Formação Docente. Revista Retratos da Escola, Brasília, v. 13, n. 25, p. 187-201, jan./mai. 2019. Disponível em: $<\mathrm{http} / /$ www.esforce.org.br> Acesso em 5 de março de 2020.

NORONHA, O. M. Epistemologia, formação de professores e Práxis educativa transformadora. QUAESTIO, Sorocaba, SP, v. 12, p. 5-24, jul. 2010a. Disponível em < http://periodicos.uniso.br/ojs/index.php/quaestio/article/view/176> Acesso em $12 \mathrm{de} \mathrm{fev}$ de 2018.

PIAUÍ. Universidade Estadual do Piauí. Projeto Pedagógico do Curso de Pedagogia. Teresina. Impresso, 2013. 
SCHEIBE, L. Diretrizes Curriculares de para o curso de Pedagogia: trajetória longa e inconclusa. Cadernos de Pesquisa. v.37, n.130, p. 43-62, jan./abr. 2007. Disponível em https://www.scielo.br/scielo.php?pid . Acesso 7/6/2018.

VAZQUEZ, A. S. Filosofia da Práxis. São Paulo. Expressão Popular, 2ª Edição, 2011.

*Antonia Alves Pereira Silva é professora Adjunta da Universidade Estadual do Piauí. Doutora em Educação pela UERJ (ProPEd/UERJ). Mestre em Educação pelo IPLAC/UESPI. Graduada em Pedagogia pela UFPI. Atua e pesquisa na área de formação de professores Curso de Pedagogia; políticas de formação docente e gestão escolar. Membro dos Grupos de Pesquisa PADEM(UERJ) e NEPES(UESPI).

E-mail: antoniaalves0416@yahoo.com.br

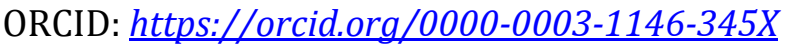

